\title{
Investigation of Low Current Gas Tungsten Arc Welding Using Split Anode Calorimetry
}

\author{
Stephan Egerland ${ }^{a, b *}$, Paul Colegrove ${ }^{a}$, and Stewart Williams ${ }^{a}$
}

Most previous split anode calorimetry research has applied high weld currents which exhibit pseudo Gaussian distributions of arc current and power density. In this paper we investigate low current arcs and show that both the current and power distributions have minima in the centre - varying significantly from the expected Gaussian profile. This was postulated due to the formation of the arc with the copper anode and the tungsten cathode. Furthermore, a number of parameters were varied including the step size between measurements, anode thickness and anode surface condition as well as cathode type and tip geometry. The step size between measurements significantly influenced the distribution profile and the anode thickness needed to be above $7 \mathrm{~mm}$ to obtain consistent results.

Keywords: Split anode; Weld calorimetry; GTAW; Arc energy; Current density; Power density, Electrode

\section{Introduction}

Low current gas tungsten arc welding (GTAW) operations often experience weld pool instabilities when joining thin sheet metal ${ }^{1}$. Understanding these phenomena is important to improve the welding process control and applicability ${ }^{1,2}$, and many investigations have focussed on the physical mechanisms ${ }^{3,4}$. Previous research has focussed on the current and power density distributions with weld currents $>100$ ampere arcs involving different experimental techniques such as spectroscopy ${ }^{5-13}$, non-invasive laser-scattering ${ }^{2,}{ }^{14-16}$, arc pressure measurement ${ }^{17-20}$, Langmuir probe $e^{21,22}$ and split anode calorimetry for GTAW ${ }^{2,4,14,}$ $15,23-27$ and Plasma Arc Welding ${ }^{28}$. In addition, numerical modelling has been extensively used to simulate gas shielded tungsten arcs and their interaction with the work piece $\mathrm{e}^{25,29-38}$.

Spectroscopic methods, provide information on the arc energy distribution which is derived from spectral analysis but has limitations for welding arc analysis ${ }^{9,}{ }^{39}$. Applying two spatial axes, a spectrum can be analysed quite precisely along its wavelength axis (x-axis); however, spectral intensity related to the $y$-axis remains difficult to quantify ${ }^{39}$.

\footnotetext{
${ }^{a}$ Department of Welding Engineering and Laser Processing, Cranfield University, Cranfield, Bedford MK43 0AL, UK

${ }^{\mathrm{b}}$ FRONIUS International GmbH, 4600 Wels, Austria

* Corresponding author: s.a.egerland@cranfield.ac.uk; Department of Welding Engineering and Laser Processing, Cranfield University, Cranfield, Bedford MK43 OAL, UK; Tel. +437242-2414930
} 
Even though suitable for welding arc analysis, the Langmuir probe technique can produce uncertain results caused by the probe, traversing through and interacting with the arc plasma $^{21}$. Finally the pressure underneath the arc can be measured and correlated to arc current density to provide valuable information on fusion depth phenomena ${ }^{18,19}$. When using this method, attention must be paid though to accurate preparation and handling of the manometers used.

Therefore the split anode calorimeter is both the best method for measuring current and power densities at the anode surface and is simple to implement. A schematic diagram of a split anode calorimeter is shown in Figure 1. Instead of a work piece material which is normally used for welding applications, two non-melting copper anodes are employed. As the welding torch is traversed across the interface or split plane between the two anodes the current flowing through each anode is measured. This may be multiplied by the arc voltage to determine the electrical power into each anode.

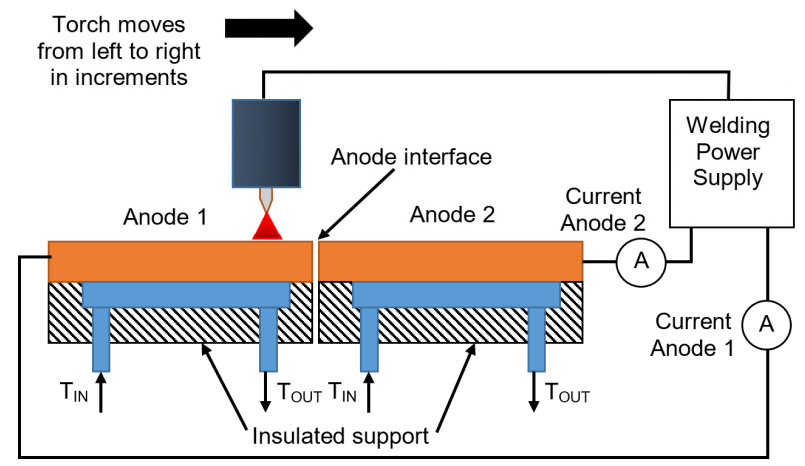

1 Schematic diagram of split anode calorimeter.

Each anode is water cooled, and the difference, $\Delta T$ between inlet $\left(T_{\text {IN }}\right)$ and outlet flow temperature ( $T_{\text {Out }}$ ) allows the power, $Q_{c a l}$ being dissipated in each anode to be determined from equation (1):

$$
Q_{c a l}=\dot{m} c_{p} \Delta T
$$

Here $\dot{m}$ is the mass flow-rate of water and $c_{p}$ is the specific heat capacity. Figure 2(a) schematically shows how the arc plasma, assumed axisymmetric, is split between the two anodes. Figure 2(b) plots the current flowing into the two anodes as the torch traverses the interface. A plot of the temperature difference, $\Delta T$ and the corresponding calorimetric power, $Q_{c a l}$ has a very similar shape. 

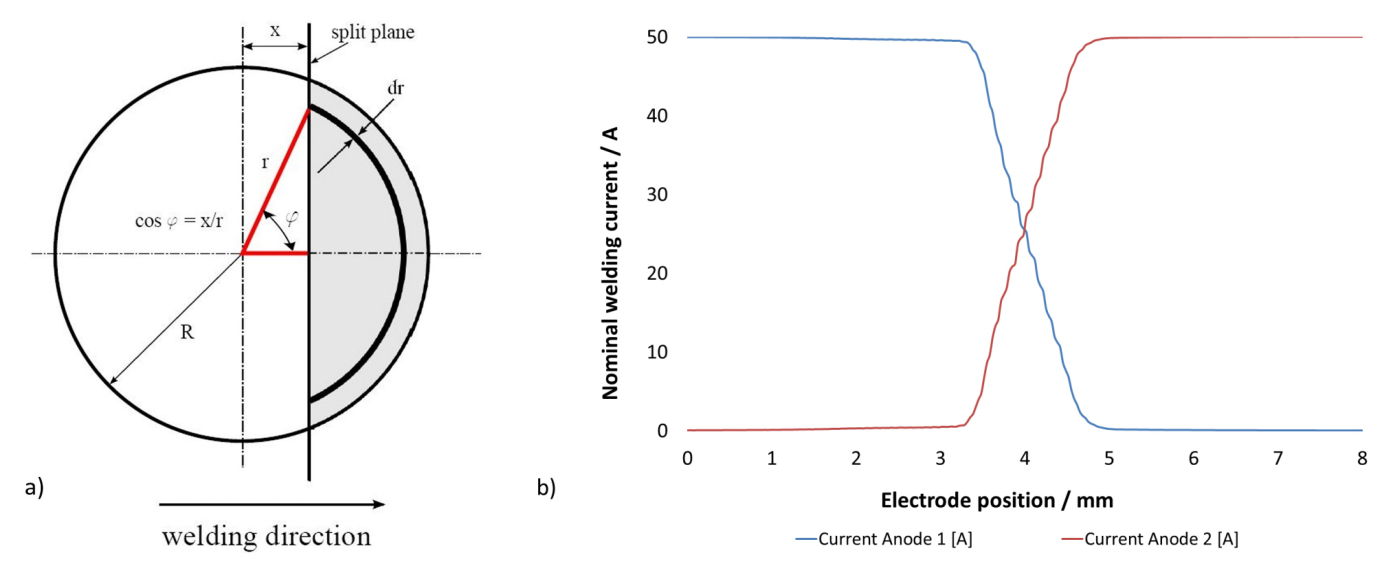

\section{$2 a$-Schematic arc plasma area split between the two anodes; $b$ typical plot of the current flux flowing into the two anodes.}

Finally, the Abel Inversion is used to determine either the current density, or power density via the electrical or calorimetric measurements and is implemented with equation (2):

$$
f(r)=\left(\frac{1}{\pi}\right) \int_{r}^{R} F^{\prime \prime}(x) /\left(x^{2}-r^{2}\right)^{1 / 2} \mathrm{dx}
$$

Where:

$r$ is the particular radius where the density is being determined;

$F^{\prime \prime}(x)$ is the second derivative of the variable whose density needs to be determined, i.e. either the current or the power. This data is provided as a function of the position, $x$;

$f(r)$ is the corresponding density of this variable as a function of the distance from the electrode centre;

$R$ is the arc radius or the starting point for the integration.

One of the advantages of the technique is there are two separate methods for calculating the power density (electrical power and calorimetric power) which can be used to validate each other. The technique was originally developed by Nestor ${ }^{23,24,40}$, and was subsequently implemented by Schoeck and Eckert ${ }^{41}$, Tsai $^{26}$, Tsai and Eagar ${ }^{42}$, Lu and Kou ${ }^{30}$, Tanaka et al. ${ }^{2,15}$ and Ushio et al. ${ }^{27}$, who demonstrated that it provides reliable data for GTAW arcs.

The aforementioned studies demonstrated Gaussian-like current density profiles under most conditions $^{2,15,27,43-45}$. There are however a few exceptions. In particular Nestor ${ }^{23}$ for high current arcs found minima in the power and current density distribution along the arc centreline when varying electrode to work piece distance (ETWD) and shielding gases. Decreasing ETWD was shown to produce minima vs. longer arcs; whereas constricting the arc, using a water cooled orifice, was observed to reduce the density minima and led to more Gaussian-like current and power density distribution. Lu and Kou ${ }^{30}$ found distributions generally steeper than Gaussian by developing a different statistical approach referred to as "non-parametric minimization". The authors state the Gaussian distribution is often a "poor approximation" of the current and power densities of welding arcs. Nevertheless all researchers agreed that the major factors influencing the density distribution were the arc 
length or arc voltage $2,23,26,42$, current level $^{2}, 15,23,24,26,27,30,41-43,45$, anode voltage fall ${ }^{41}$, ambient gas pressure ${ }^{23}$, electrode diameter, geometry and type ${ }^{2,23,24,26,27,30,42}$, and shielding gas composition $2,23,24,26,27,42$.

To the best knowledge of the authors none of the previous split anode studies have investigated combinatory effects of low currents, step size used for the data acquisition, thickness of the anode, effects of anode surface oxidation or tungsten electrode geometry and type. Therefore this study seeks to understand how each of the above factors influence the current and power density distributions measured with the calorimeter.

\section{Methodology}

Figure 1 schematically shows the design of the calorimeter whose base was constructed of temperature resistant glass fibre reinforced polyamide. A cooling channel was machined into the calorimeter body, being mechanically joined to an insulating sheet of Synthetic Resin Bonded Paper (SRBP) and rigidly fixed to a metallic gantry equipped with hardware for connecting the data acquisition system and thermocouples. The calorimeter was equipped with two precisely machined ( $80 \mathrm{~mm} \times 62 \mathrm{~mm}$ ) oxygen-free copper anodes which had thicknesses of either 3,7 , or $12 \mathrm{~mm}$. The gap between the anodes was set using heat and electrical resistant polyimide film (DuPont ${ }^{\circledR}$ KAPTON $^{\circledR} \mathrm{HN}^{\prime} 3$ mil') which consistently provided a uniform gap width of $75 \mu \mathrm{m}$. Prior to every experiment the anodes were prepared by manual longitudinal wet-grinding with 500-grit abrasive paper. Subsequently 'Scotch-Brite ${ }^{\circledR \prime}$ scouring pads were used for longitudinal polishing, achieving a smooth surface structure and to remove any oxides that formed during previous experiments.

A GTAW power source (Fronius Magic Wave 2200) equipped with a cooling unit (Fronius FK 2200) and water cooled torch (Fronius TTW 3000a F/F++/UD/4m) was used for the experiments. To achieve sound gas shielding a large internal diameter nozzle $(\varnothing 19.0 \mathrm{~mm}$ ) with a gas lens was used. Most experiments used a $2 \% \mathrm{Ce}(\mathrm{IV})$-oxide $\left(\mathrm{CeO}_{2}\right)$ doped electrode type (WC20) which had a diameter of $2.4 \mathrm{~mm}$ with a vertex angle of $36^{\circ}$. An electrode to work piece distance of $3.0 \mathrm{~mm}$ and an electrode extension from the shielding gas nozzle exit of $6.0 \mathrm{~mm}$ were kept constant throughout all experiments. The shielding gas was argon (purity 99.996\%) with $7.0 \mathrm{I} \mathrm{min}^{-1}$ flow-rate.

Since very accurate positioning of the torch relative to the anodes was desired; an 'IAI RCA 2 SA3C' high precision linear actuator was used with a repeat accuracy of $0.05 \mathrm{~mm}$. A 20 channel multiplexer data acquisition system (Type: Agilent 34790a) was employed. The equipment operated in the following way:

- The manipulator positioned the torch.

- A delay time of 10 seconds was applied before any data collection occurred. This was done to allow the system to stabilise - particularly the water inlet and outlet temperatures.

- The data logger was then triggered and 5 measurements were taken with a delay of 1 second between each measurement.

- A second delay of 0.5 seconds was applied before the manipulator moved the torch to the next position. Increment sizes of $0.1,0.2$ and $0.5 \mathrm{~mm}$ were investigated in this study. 
The experimental matrix is shown in Table 1. The effects of increment; anode thickness; anode surface oxidation; electrode tip geometry and electrode type were investigated.

\begin{tabular}{|c|c|c|c|c|c|}
\hline $\begin{array}{c}\text { Trial } \\
\text { Description }\end{array}$ & $\begin{array}{c}\text { Anode } \\
\text { Thickness } \\
\text { [mm] }\end{array}$ & $\begin{array}{l}\text { Increment } \\
{[\mathrm{mm}]}\end{array}$ & $\begin{array}{c}\text { Weld Current } \\
\text { [A] }\end{array}$ & Remarks & $\begin{array}{l}\text { ETWD } \\
\text { [mm] }\end{array}$ \\
\hline \multirow{3}{*}{ Increment } & \multirow{3}{*}{7.0} & 0.1 & \multirow{3}{*}{50} & \multirow{3}{*}{ - } & \multirow{9}{*}{3.0} \\
\hline & & 0.2 & & & \\
\hline & & 0.5 & & & \\
\hline \multirow{3}{*}{$\begin{array}{c}\text { Anode } \\
\text { Thickness }\end{array}$} & 3.0 & \multirow{3}{*}{0.2} & 50 & \multirow{3}{*}{ - } & \\
\hline & 7.0 & & 75 & & \\
\hline & 12.0 & & 100 & & \\
\hline Surface & 3.0 & 0.2 & 50 & $\begin{array}{l}\text { Oxidised } \\
\text { surface }\end{array}$ & \\
\hline $\begin{array}{l}\text { Electrode } \\
\text { Geometry }\end{array}$ & 12.0 & 0.2 & 50 & $\begin{array}{l}\text { Truncated tip, } \\
\text { see Figure } 3(b)\end{array}$ & \\
\hline $\begin{array}{l}\text { Electrode } \\
\text { Composition }\end{array}$ & 12.0 & 0.2 & 50 & $\begin{array}{l}\text { Pure Tungsten } \\
\text { vs. } \mathrm{CeO}_{2} \text { doped } \\
\text { Tungsten (WC20) }\end{array}$ & \\
\hline
\end{tabular}

Table 1 Parameters used for the split anode experiments.

Figure 3(a) shows the calorimeter setup and Figure 3(b) depicts the truncated electrode design. Two measurements were conducted for each condition. Due to the small increments and number of samples collected, each measurement took about 22 minutes for the larger step; approaching 45 minutes for the smallest increment size.

The results were processed with 'Microsoft Excel ${ }^{\circledR}$ '. The derivative of the measured data $\mathrm{F}^{\prime}(\mathrm{x})$ was determined numerically with Lagrange's five-point formula according to equation (3):

$$
F_{2}^{\prime}(x)=\frac{1}{12 \Delta l}\left(f_{0}-8 f_{1}+8 f_{3}-f_{4}\right)
$$

where $\Delta l$ is the increment size, and $f_{i}$ is the raw data at a particular position, $i$. The five point formula was used to help smooth out noise. Additional smoothing was applied by calculating the average of four values of the derivative $F_{i}{ }^{\prime}(x)$. This procedure (with smoothing) was applied twice to obtain the second derivative. 

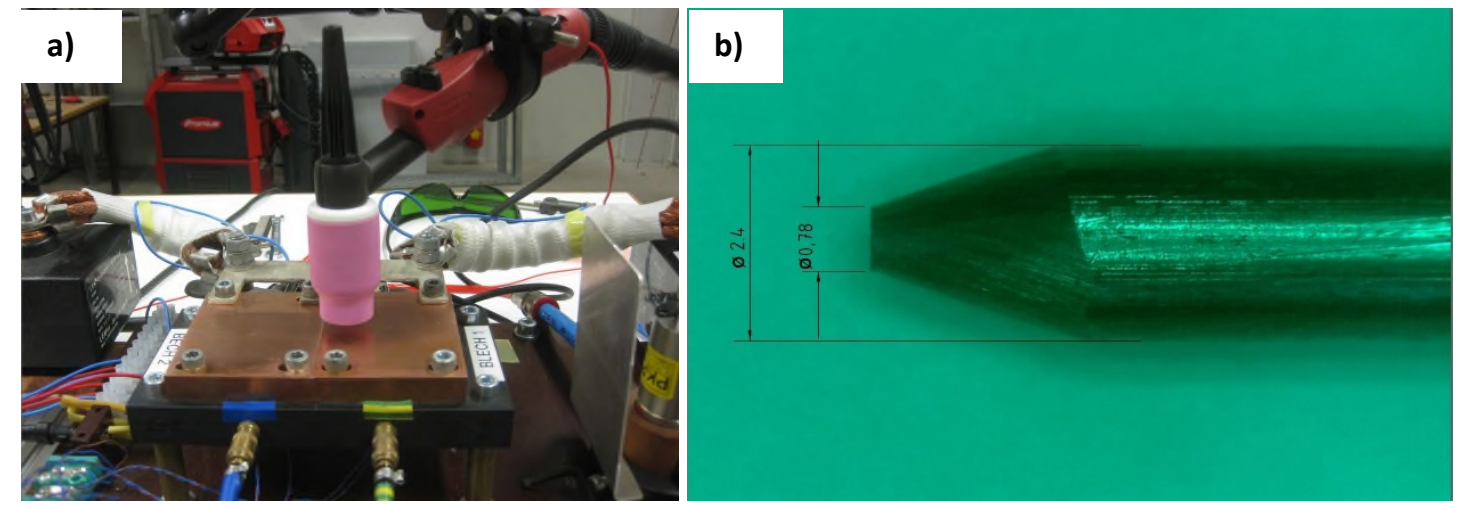

$a$ - Photo showing the experimental setup; $b$ truncated electrode tip.

\section{Results}

\subsection{Anode characteristics}

Figure 4(a) shows the raw data of the current vs. position for the different increment sizes for $7 \mathrm{~mm}$ anode thickness. In addition it shows the second derivative of this data. Although the raw data was similar for the three increment sizes, there is clearly a large difference in the second derivative which affected the calculation of the current density from the Abel inversion in Figure 4(b).

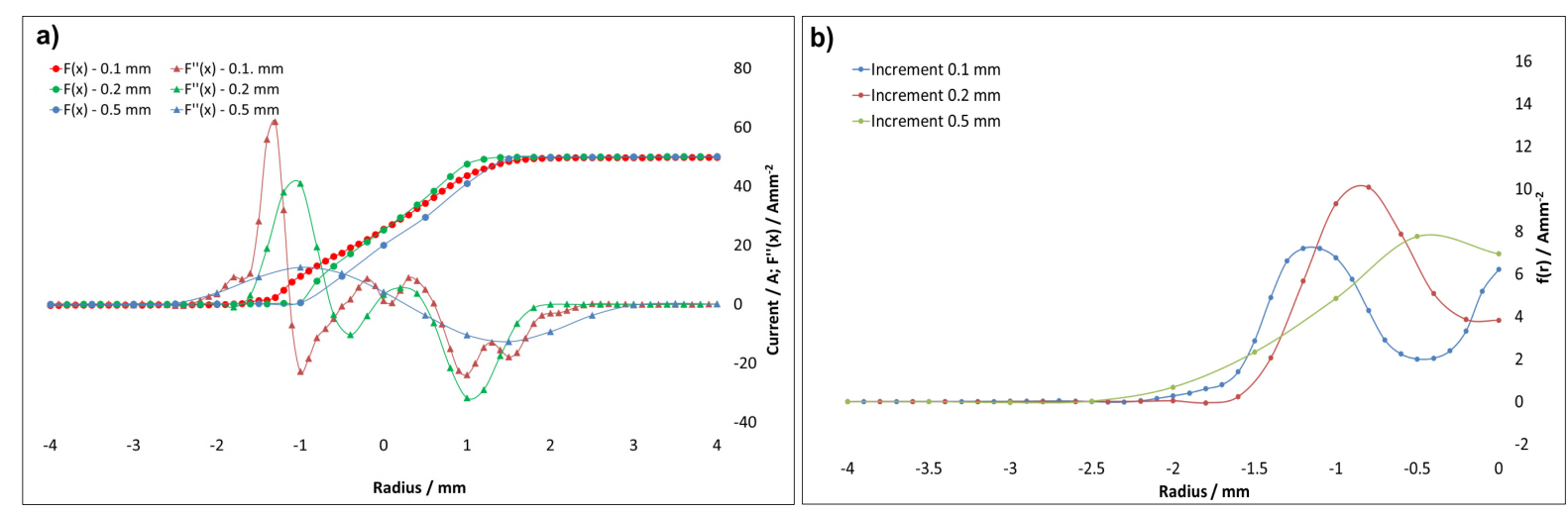

4 Plots showing the effect of the manipulator increment: $a$ - Raw data for anode 1 showing current and second derivative of current vs. position; $b$ corresponding current density distribution for 50 ampere nominal weld current and an anode thickness of $7 \mathrm{~mm}$.

When using the large step size the power intensity approached a Gaussian curve, while the smaller step sizes indicated that the maximum occurred away from the centreline. Therefore the increment size has a significant effect on the profile for this current level.

The effect of the anode thickness on the current density for the 100 ampere nominal currents is shown in Figure 5(a). The values for the $7 \mathrm{~mm}$ and $12 \mathrm{~mm}$ thickness anodes were very similar while the values for the $3 \mathrm{~mm}$ were significantly different. Overheating effects were observed with the $3 \mathrm{~mm}$ anode and 100 ampere nominal current due to the poorer thermal dissipation with the thinner material. Therefore the temperature of the anode appears to have had a significant effect on the current intensity profile. At lower currents all anode thicknesses gave very similar results. 


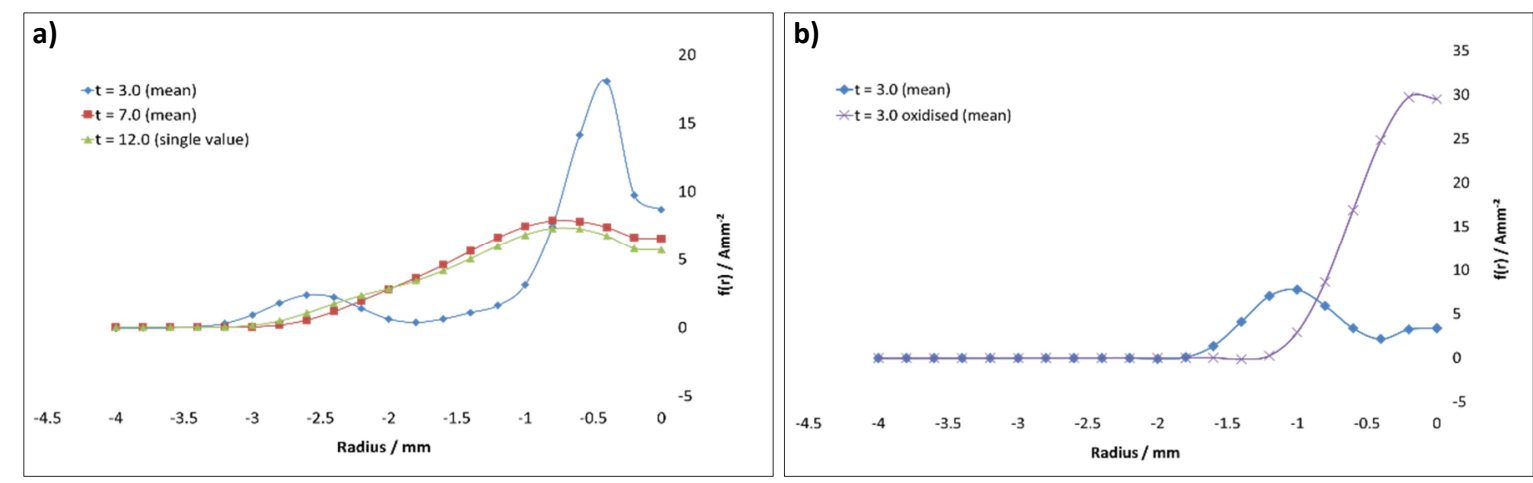

$5 \quad a$ - Current density as a function of the anode thickness for a welding current of 100 ampere; $\boldsymbol{b}$ the surface condition for a nominal current of 50 ampere.

A plot showing the effect of the anode surface condition is shown in Figure $5(\mathrm{~b})$. This demonstrates how the presence of the surface oxide resulted in a narrower arc with a higher intensity in the centre.

\subsection{Effects of welding parameters}

A plot of the current density as a function of the welding current is shown in Figure 6(a) and the corresponding plots of the power densities which are calculated from the welding power input and the calorimeter power input are shown in Figure 6(b). Collectively these figures illustrate how increasing the current widens the arc while the current and power densities remain quite similar. In addition, the shape of the power density from the weld power input and the calorimeter were very similar providing confidence in both measurements and adding validity to the minima observed in the centre of the 50 ampere arc. Process efficiency defined as the ratio of calorimetric power over electrical power was found to be 0.81 (50 ampere); 0.82 (75 ampere) and 0.8 (100 ampere) and is similar to values reported by Stenbacka ${ }^{46}$.

Finally, the results for the three electrode types are shown in Figure 6(c). Like the oxidised anode surface condition this also has a significant impact on the current distribution, with the current density being concentrated at the centre of the arc for the truncated cone and being fairly wide and flat for pure tungsten. Additionally we could observe cathode tip changes after welding. For example Figure $6(\mathrm{~d})$ shows the electrode tip after applying 50 ampere weld current for $\sim 1.32 \times 10^{3}$ seconds.

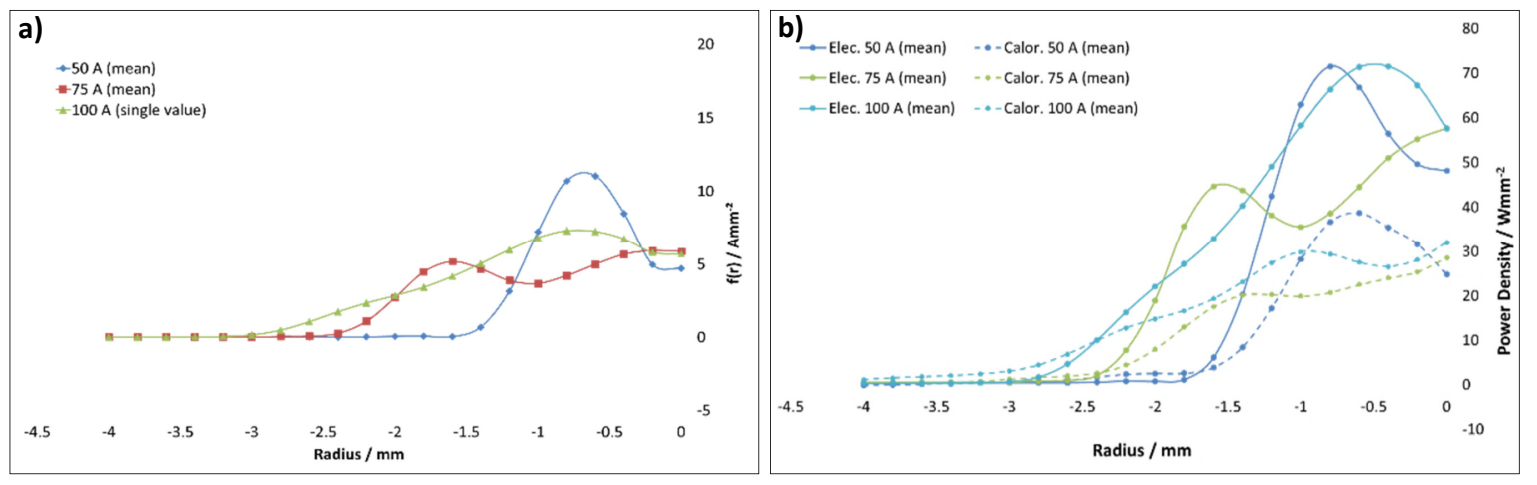




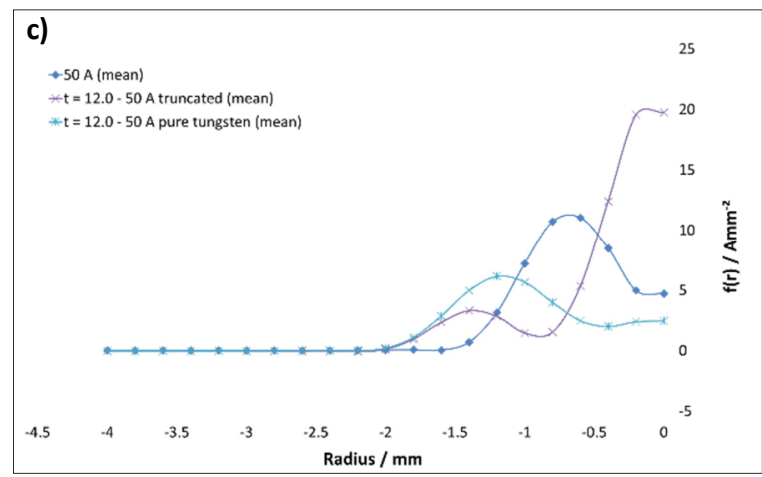

d)

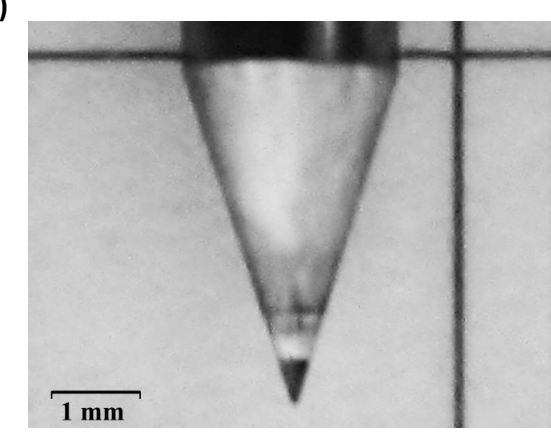

6 Plots showing the effect of the welding current on $a$ current density; $b$ power density from welding power supply and calorimeter; $c$ effect of cathode geometry and composition on current density and $d$ cathode tip after welding. Note: anode thickness for all plots was $12.0 \mathrm{~mm}$.

\section{Discussion}

Our results on the effect of the increment in Figure 4 demonstrate that large increment sizes $(0.5 \mathrm{~mm})$ lead to a current density profile that approaches a Gaussian shape and thereby confirms results achieved by Tanaka et al. $^{2}$, Tsai $^{26}$, Tsai and Eagar ${ }^{42}$, Ushio et al. ${ }^{27}$. However, the current density with smaller increments is clearly different and demonstrates that this is an important parameter when undertaking split anode measurements. The increment size needs to be sufficiently small to capture the detailed shape of the density distribution being investigated. However, the smaller the increment size, the more susceptible the data is to noise in the measurements due to the calculation of the second derivative. This is evident in the data for the $0.1 \mathrm{~mm}$ increment and its corresponding derivative in Figure 4(a). While second derivatives for the 0.2 and $0.5 \mathrm{~mm}$ increments are symmetric about the centreline, the data for the $0.1 \mathrm{~mm}$ increment is not, suggesting that it is more likely to be subject to noise or other effects. This is why the $0.2 \mathrm{~mm}$ increment was used for all the subsequent studies.

The minima in the current and power densities around the centre of the arc with low currents is an interesting finding. Heberlein and Pfender ${ }^{47}$, spectroscopically investigating the anode boundary layer of a 100 ampere atmospheric pressure argon arc have found the electron density maxima shifted $\sim 1.5 \mathrm{~mm}$ away from the cathode centre. Tanaka et al. ${ }^{2}$, provided results which, in part, also showed that there was a current density maximum close to, but not exactly at the arc centre - although plotted a line of best fit that used a Gaussianlike profile. Lu et al. ${ }^{32}$ have numerically modelled a non-Gaussian distribution, showing a distinct heat flux drop at, but a density peak shifted $\sim 1 \mathrm{~mm}$ away from the arc centre. Therefore our results support findings which have been reported elsewhere, although their significance was not highlighted.

The Abel inversion approach is particularly sensitive to experimental error and/or noise, due to the double differentiation of the measured data ${ }^{26,47}$. Appropriate smoothing, recommended by $\mathrm{Tsai}^{26}$ was used to overcome this, however, checks were done to ensure that the overall result is not affected by this smoothing procedure. Figure 7(a) shows the difference between the smoothed and unsmoothed data for the 50 ampere arc. This shows how the data refinement process used throughout this study has reduced the noise (and magnitude) of the curve, but it has not fundamentally altered the presence of the off-axis maximum. 
According to the results from Richardson ${ }^{48}$, consistent anode surface conditions were found essential for achieving reproducible measurements. Work piece imperfections can interfere with the measurements, particularly with low current arcs. While crossing the anode gap the arc can stick to the hot (and possibly slightly oxidised) anode before jumping across to the new anode. This phenomenon, reported elsewhere and called pinning ${ }^{48}$, can influence measurement output and calculated results. No deflection ("arc pinning") was visually observed throughout our experiments. To confirm this, Figure 7 (b) compares the plots of the arc intensity from the two anodes and shows that while not identical, they are remarkably similar and both show the off-axis peak. Nevertheless future work will further improve the anode surface quality (machine polishing) and implement a high definition rate camera to optically evaluate any arc disturbance at the splitting interface for assuring meaningful data and to confirm our present findings.

Our results showed the current and power density maximum away from the arc axis disappeared with increasing current, simultaneously joined by widening the anode spot. The latter supports the work of Tanaka and Ushio ${ }^{14}$ who stated that the arc current level significantly influences the heat transfer conditions via the anode boundary layer. Compared with the 50 ampere arc, doubling the nominal current led to a more Gaussian-like distribution profile. Although Lu et al. ${ }^{32}$ calculated heat flux minima at the arc centre, their simulation nonetheless showed the peaks even for their 200 ampere arc model, which would contradict the suggested maxima dissipation with increasing current. However, the authors used a different cathode diameter; electrode vertex angle; ETWD and gas flow-rate for their model compared to our experimental conditions.

One possible reason for the off-axis maxima is the way the arc is formed between the electrode and the anode. Ushio et al. ${ }^{3}$ observed reduced dopant concentration levels near the tip of $\mathrm{ThO}_{2}, \mathrm{La}_{2} \mathrm{O}_{3}$, and $\mathrm{Y}_{2} \mathrm{O}_{3}$ doped tungsten electrodes but not $\mathrm{CeO}_{2}$. Cerium-oxide doped electrodes were used for this study. Dopant depletion in this region may result in an arc being created with the sides of the electrode - which have a lower work function rather than the tip as shown in Figure 8 . This would create the off-axis maxima observed in the experiments. It is not clear why this effect is lost with higher currents. We assume however higher currents to cause a more uniform temperature profile throughout the cathode tip cross section which may promote the diffusion of dopant elements from the inner cathode to its surface. This again may lead to a more Gaussian-like density distribution profile.

The oxidised anode surface results confirmed the findings from Fihey and Simoneau ${ }^{1}$ who proposed that elements with high electron affinity (e.g. oxygen) form negative ions which constrict the anode spot and increase penetration depth. The authors ${ }^{1}$ varied the amount of oxygen in the shielding gas and measured higher arc voltage with rising the oxygen content. Although this arc voltage increase with an oxidised surface was not found in our investigations, our calculations showed an arc plasma constriction and increased current density towards the arc axis; which would affect the penetration profile in regular GTAW (melting anodes) as claimed by Majetich and $\mathrm{Yeo}^{49}$. 


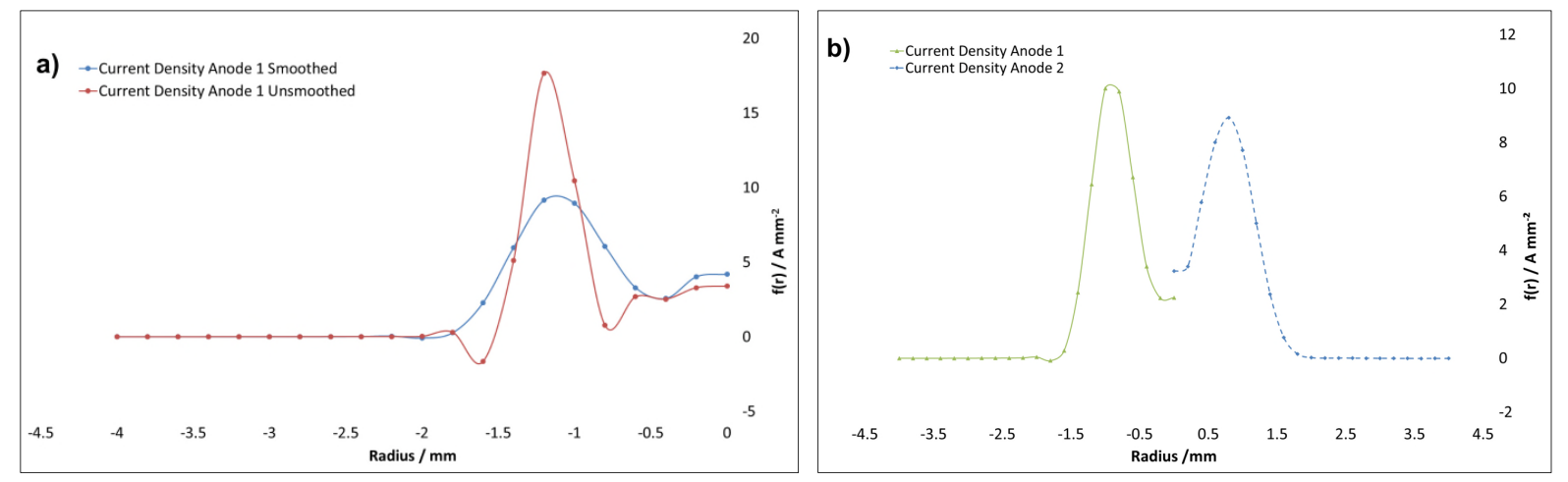

$7 \quad a$ - Current density distribution before and after smoothing and $b$ comparison of the current density from the two anode halves. Both are for a $\mathbf{5 0}$ ampere welding arc.

Our findings on cathode tip truncation contradict the work from Bernáth et al. ${ }^{50}$ who have not found measurable variations in the plasma shape of gas tungsten arcs when applying either a pointed or tapered cathode. However, we suggest our results are confirmed by Sadek et al. $^{51}$ and $\mathrm{Key}^{52}$, who stated that there are differences between pointed and truncated electrode tips. Also Ushio et al. ${ }^{3}$ found differences by blunting the electrode tip and attributed these to a variation of the current density near to the cathode which changed the induced plasma flow impedance. This, in turn, changed the arc force acting on the anode surface. Therefore we suggest that truncating the electrode may lead to changes in the arc to work piece interaction and lead to differences in the real weld penetration profile, which would confirm findings by Key ${ }^{52}$ and $\mathrm{Kou}^{53}$.

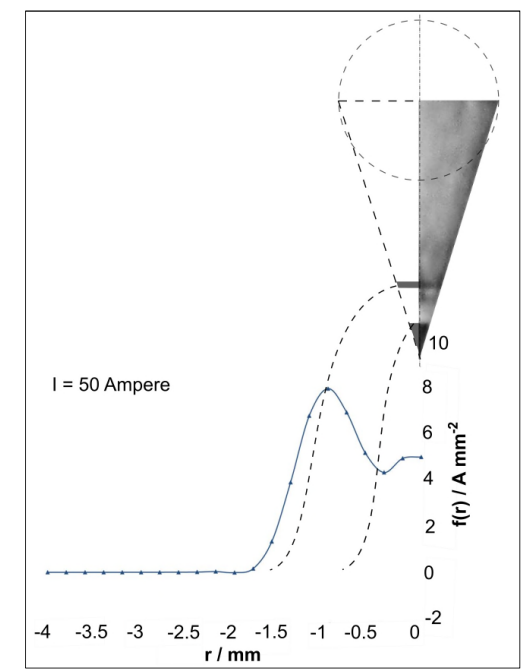

8 Schematic plot of current density distribution of a $\mathbf{5 0}$ ampere arc with off-axis maximum depending on electrode tip dopant depletion. Note. Right half of the schematic tungsten electrode depicted is taken from the real photographic image (Fig. $6 d$ ).

\section{Conclusions}

From the investigations conducted we can draw the following conclusions:

1. The split anode calorimeter used is suitable for obtaining reliable data from low current GTAW arc measurements.

2. The increment size for traversing the arc across the anodes has a significant impact on the calculated current density distributions. 
3. The smallest increment size $(0.1 \mathrm{~mm})$ was subjected to greater noise when calculating the second derivative and showed a very distinct final density plot with a significant density maximum away from the arc axis.

4. The largest increment $(0.5 \mathrm{~mm})$ was found to approach a Gaussian density profile, which has been reported by other researchers.

5. Increasing the weld current widens the anode spot diameter, causes the density peak away from the arc centre to disappear and results in a Gaussian-like distribution profile.

6. Oxidised anode surfaces resulted in arc constriction with significantly increased current density close to the arc centre.

7. Truncated cathode tips led to a higher current density close to the arc axis.

8. Pure tungsten showed the flattest current density profile vs. $\mathrm{CeO}_{2}$-doped tungsten cathodes.

9. Electrode dopant depletion may explain the minima found in the arc centre current and power density distribution.

\section{Acknowledgements}

The authors are grateful to FRONIUS International, Wels, Austria, for producing the split anode calorimeter and granting access to laboratory and equipment. Special gratitude shall be devoted to two colleagues in the Fronius R\&D department: Mr Andreas Leonhartsberger for his personal assistance in the design of the calorimeter and his friendly and unselfish support during the experiments; and Mr Daniel Angermayr, for his support in writing the manipulator control software. Finally special thanks are attributed to the peer reviewers for their valuable comments.

\section{References}

1. J. Fihey and R. Simoneau: 'Weld Penetration Variation in GTA Welding of some $304 \mathrm{~L}$ Stainless Steels', 'Proc. Welding Technology for Energy Applications', Gatlinburg, TN, May, 1982, Session D. Gas Shielded Processes, 139-153.

2. M. Tanaka, H. Terasaki, H. Fujii, M. Ushio, R. Narita, and K. Kobayashi: 'Anode Heat Transfer in TIG Welding and its Effect on the Cross-Sectional Area of Weld Penetration' Weld. Int., 2006, 20(4), 268-274.

3. M. Ushio, M. Tanaka and F. Matsuda: 'Proc. Physical Aspects of Arc Welding', Glasgow (UK), September 1993, Delftse Uitgevers Maatschappij, Paper 3, 25-42.

4. M. Tanaka and J. J. Lowke: 'Predictions of weld pool profiles using plasma physics' J. Phys. D: Appl. Phys., 2007, 40(1), R1-R23.

5. H. Olsen: 'Thermal and Electrical Properties of an Argon Plasma' Phys. Fluids, 1959, 2(6), 614-623.

6. H. Olsen: 'The Electric Arc as a Light Source for Quantitative Spectroscopy' J. Quant. Spectrosc. Ra., 1963, 3(4), 305-333.

7. M. Thornton: 'Spectroscopic Determination of Temperature Distributions for a TIG Arc' J. Phys. D: Appl. Phys., 1993, 26(9), 1432.

8. P. Vervisch, B. Cheron, and J. Lhuissier: 'Spectroscopic Analysis of a TIG Arc Plasma' J. Phys. D: Appl. Phys., 1990, 23(8), 1058.

9. L. O. Vilarinho and A. Scotti: 'Proposal for a modified Fowler-Milne Method to determine the Temperature Profile in TIG Welding at low Currents' J. Braz. Soc. Mech. Sci. \& Eng., 2004, 26(1), 34-39. 
10. M. Weglowski: 'Determination of GTA and GMA Welding Arc Temperatures' Weld. Int., 2005, 19(3), 186-192.

11. G. Haddad and A. Farmer: 'Temperature Determinations in a free-burning Arc. I. Experimental Techniques and Results in Argon' J. Phys. D: Appl. Phys., 1984, 17(6), 1189.

12. A. Farmer, G. Haddad, and L. Cram: 'Temperature determinations in a free-burning arc. III. Measurements with molten anodes' J. Phys. D: Appl. Phys., 1986, 19(9), 1723.

13. D. Degout and A. Catherinot: 'Spectroscopic analysis of the plasma created by a double-flux tungsten inert gas (TIG) arc plasma torch' J. Phys. D: Appl. Phys., 1986, 19(5), 811.

14. M. Tanaka and M. Ushio: 'Plasma State in free-burning Argon Arc and its Effect on Anode Heat Transfer' J. Phys. D: Appl. Phys., 1999, 32(10), 1153.

15. M. Tanaka and M. Ushio: 'Observations of the Anode Boundary Layer in free-burning Argon Arcs' J. Phys. D: Appl. Phys., 1999, 32(8), 906.

16. H. Terasaki, M. Tanaka, and M. Ushio: 'Effects of Metal Vapor on Electron Temperature in Helium Gas Tungsten Arcs' Metall. Mater. Trans. A, 2002, 33(4), 1183-1188.

17. K. Hiraoka, A. Okada, and M. Inagaki: 'Effect of Electrode Geometry on Maximum Arc Pressure in Gas Tungsten Arc Welding' Q. J. Jpn. Weld. Soc., 1985, 3(2), 246-252.

18. D. S. Oh, Y. S. Kim, and S. M. Cho: 'Derivation of Current Density Distribution by Arc Pressure Measurement in GTA Welding' Sci. Technol. Weld. Join., 2005, 10(4), 442446.

19. H. S. Ham, D. S. Oh, and S. M. Cho: 'Measurement of arc pressure and shield gas pressure effect on surface of molten pool in TIG welding' Sci. Technol. Weld. Join., 2012, 17(7), 594-600.

20. K. Kobayashi, Y. Nishimura, T. Iijima, M. Ushio, M. Tanaka, J. Shimamura, Y. Ueno, and M. Yamashita: 'Practical Application of High Efficiency Twin-Arc TIG Welding Method (SEDAR-TIG) for PCLNG Storage Tank' Weld. World, 2004, 48(7-8), 35-39.

21. C. Fanara: 'A Langmuir Multi-Probe System for the Characterization of Atmospheric Pressure Arc Plasmas', PhD Thesis, Cranfield University, Cranfield, UK, 2003.

22. C. Fanara and I. M. Richardson: 'A Langmuir multi-probe system for the characterization of atmospheric pressure arc plasmas' J. Phys. D: Appl. Phys., 2001, 34(18), 2715-2725.

23. O. H. Nestor: 'An Experimental Determination of Current Density and Heat Transfer Intensity Distributions at the Anode of High Current, Inert Gas Arcs', PhD Thesis, University of Buffalo, Buffalo, NY, 1959.

24. O. H. Nestor: 'Heat Intensity and Current Density Distributions at the Anode of High Current, Inert Gas Arcs' J. Appl. Phys. D, 1962, 33(5), 1638-1648.

25. M. Tsai and S. Kou: 'Heat Transfer and Fluid Flow in Welding Arcs produced by Sharpened and Flat Electrodes' Int. J. Heat Mass Transf., 1990, 33(10), 2089-2098.

26. N. Tsai: 'Heat Distribution and Weld Bead Geometry in Arc Welding', PhD Thesis, Massachusetts Institute of Technology, Massachusetts, USA, 1983.

27. M. Ushio, M. Tanaka, and J. J. Lowke: 'Anode Melting from free-burning Argon Arcs' IEEE T. Plasma Sci., 2004, 32(1), 108-117.

28. I. Richardson: 'Properties of the Constricted Gas Tungsten (Plasma) Welding Arc at Elevated Pressures', PhD Thesis, Cranfield University, Cranfield, UK, 1991.

29. K. Biswas: 'A numerical prediction of the temperature distribution in the thermionic cathode of a welding arc' J. Mater. Process. Tech., 1994, 40(1), 219-237. 
30. M. Lu and S. Kou: 'Power and Current Distributions in Gas Tungsten Arcs' Weld, J., 1988, 67(2), 29s-34s.

31. F. Lu, S. Yao, S. Lou, and Y. Li: 'Modeling and Finite Element Analysis on GTAW ArC and Weld Pool' Comp. Mater. Sci., 2004, 29(3), 371-378.

32. F. Lu, X. Tang, H. Yu, and S. Yao: 'Numerical Simulation on Interaction between TIG Welding Arc and Weld Pool' Comp. Mater. Sci., 2006, 35(4), 458-465.

33. M. A. Ramírez, G. Trapaga, and J. McKelliget: 'A comparison between different numerical formulations for welding arc representations' J. Mater. Process. Tech., 2004, 155-156, 1634-1640.

34. A. B. Murphy, M. Tanaka, K. Yamamoto, S. Tashiro, J. J. Lowke, and K. Ostrikov: 'Modelling of Arc Welding: The Importance of including the Arc Plasma in the Computational Domain' Vacuum, 2010, 85(5), 579-584.

35. L. Cram, L. Poladian, and G. Roumeliotis: 'Departures from equilibrium in a freeburning argon arc' J. Phys. D: Appl. Phys., 1988, 21(3), 418.

36. H. Fan, H.-L. Tsai, and S. Na: 'Heat transfer and fluid flow in a partially or fully penetrated weld pool in gas tungsten arc welding' Int. J. Heat Mass Transf., 2001, 44(2), 417-428.

37. C. Wu and J. Gao: 'Analysis of the Heat Flux Distribution at the Anode of a TIG Welding Arc' Comp. Mater. Sci., 2002, 24(3), 323-327.

38. C. Wu, M. Ushio, and M. Tanaka: 'Analysis of the TIG Welding Arc Behavior' Comp. Mater. Sci., 1997, 7(3), 308-314.

39. K. Behringer, Einführung in die Plasmaspektroskopie, in Lecture Script, Universität Augsburg, Germany. 2000.

40. O. Nestor and H. Olsen: 'Numerical Methods for reducing Line and Surface Probe Data' SIAM review, 1960, 2(3), 200-207.

41. P. Schoeck and E. Eckert: 'An Investigation of Anode Heat Transfer in High Intensity Arcs', 'Proc. Ionization Phenomena in Gases', Munich, Germany 1962, 1812-1829.

42. N. Tsai and T. Eagar: 'Distribution of the Heat and Current Fluxes in Gas Tungsten Arcs' Metall. Tans. B, 1985, 16(4), 841-846.

43. J. Wilkinson and D. Milner: 'Heat Transfer from Arcs' Brit. Welding J., 1960, 7(2), 115124.

44. P. A. Schoeck: 'An Investigation of the Anode Energy Balance of High Intensity Arcs in Argon', in 'Modern Developments in Heat Transfer', 353-400; 1963, New York, USA, Academic Press New York.

45. R. C. Eberhart and R. Seban: 'The energy balance for a high current argon arc' Int. J. Heat Mass Transf., 1966, 9(9), 939-949.

46. N. Stenbacka: 'On arc efficiency in Gas Tungsten Arc Welding' Soldagem Insp., 2013, 18(4), 380-390.

47. J. Heberlein and E. Pfender: 'Investigation of the Anode Boundary Layer of an Atmospheric Pressure Argon Arc' IEEE T. Plasma Sci., 1977, 5(3), 171-180.

48. D. I. M. Richardson: Delft Technical University, NL, 24 July 2012: Personal communication 24 July 2012.

49. J. C. M. a. R. B. G. Yeo: 'Method of Welding Stainless Steel US 3584187 A', Patent, USA, 1971.

50. A. Bernáth, H. Marton, and J. Dobránszky: 'Characterization of the plasma shape of the TIG welding arc', 'Proc. 3rd International Conference on Thermal Process Modelling and Simulation ', Budapest, Hungary, April 2006, International Federation for Heat Treatment and Surface Engineering. 
51. A. Sadek, M. Ushio, and F. Matsuda: 'Gas-Tungsten-Arc Cathode and related Phenomena' Trans. JWRI, 1987, 16(1), 195-210.

52. J. Key: 'Anode/Cathode Geometry and Shielding Gas Interrelationships in GTAW' Weld J., 1980, 59(12), 364-s-370-s.

53. S. Kou: 'Welding Metallurgy'; 2nd edn, 98-103; 2003, Hoboken, N.J., WileyInterscience. 
2016-05-27

\section{Investigation of low current gas tungsten arc welding using split anode calorimetry}

\section{Egerland, Stephan}

Taylor and Francis

S. Egerland, P. Colegrove and S. Williams. Investigation of low current gas tungsten arc welding using split anode calorimetry. Science and Technology of Welding and Joining. Volume 22,

2017, Issue 1, pp71-78

http://dx.doi.org/10.1080/13621718.2016.1189214

Downloaded from Cranfield Library Services E-Repository 